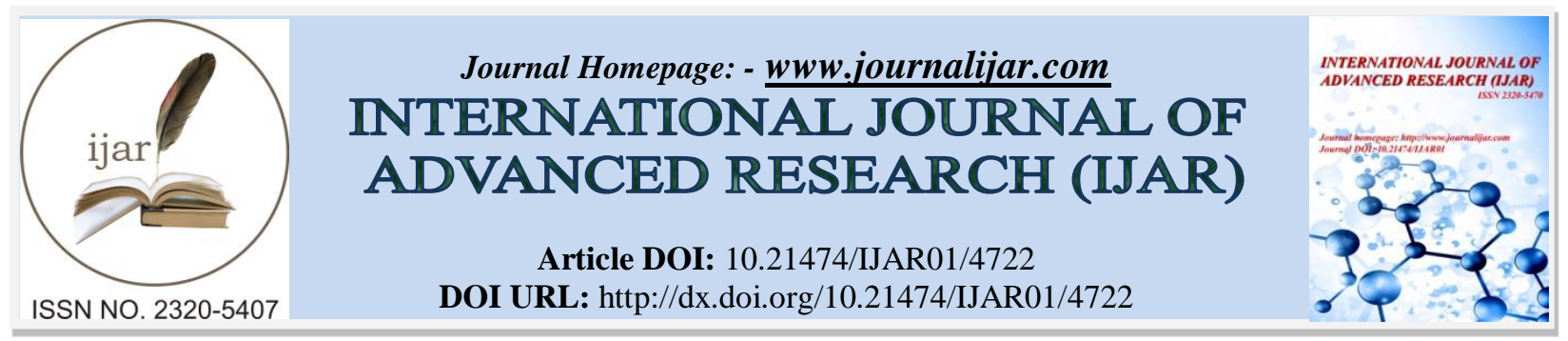

RESEARCH ARTICLE

\title{
MAJOR CHALLENGES OF IMPLEMENTING THE PROVISIONS OF WHO FRAMEWORK CONVENTION ON TOBACCO CONTROL (FCTC) IN INDIA.
}

\author{
Ms. Shweta Bhardwaj ${ }^{1}$ and ${ }^{*}$ Mr. Rajnish Ranjan Prasad ${ }^{2}$. \\ 1. University of Edinburgh, 118, Kamakshi Apartments, Plot No-28, Sector-6, Dwarka. New Delhi. \\ 2. UNFPA, 29, Sirirampura colony, Civil lines, Jaipur - 302006.
}

\section{Manuscript Info}

Manuscript History

Received: 4 May 2017

Final Accepted: 6 June 2017

Published: July 2017

Key words:-

WHO FCTC, Tobacco control, Tobacco

challenges, Tobacco policy, Tobacco

control and implementation.

\begin{abstract}
It is important to understand the challenges faced in effective implementation of WHO Framework convention on tobacco control (FCTC) in India, for reducing tobacco epidemic and its future health and financial consequences. To accomplish this task, the literature review was performed by using an extensive and wide ranging peer review (in four bibliographic databases) literature, policy documents and reports. The main challenges to effective implementation of WHO FCTC are: (a) Ineffective tobacco control enforcement, weak capacity and limited resources for implementation in states, (b) Pattern of tobacco consumption with high prevalence and availability of smokeless forms of tobacco and, (c) Opposition by industry to tobacco control legislation resulting in delay and dilution of the provisions under WHO FCTC in India. Thus, there is a need for increased financial and human resources for tobacco control, sustained advocacy and capacity building for enforcement, and strengthening of monitoring and enforcement mechanisms for WHO FCTC in India.
\end{abstract}

Copy Right, IJAR, 2017,. All rights reserved.

\section{Introduction:-}

The WHO Framework convention on tobacco control (FCTC) was the first comprehensive public health response to the global and dynamic nature of tobacco epidemic (WHO, 2003 (a)). It contains core tobacco demand reducing provisions under article 6-14 and tobacco supply reducing measures under article 15-17 (WHO, 2003 (a)). Globally, a reduction of $30 \%$ in the prevalence of tobacco use by 2025 , is one of the nine agreed upon targets and critical elements of the WHO global action plan for the prevention and control of non-communicable diseases (NCDs) 2013 - 2020 (WHO, 2013 (a)). At the national level, the national plan of action on control of NCDs aims to reduce the prevalence of tobacco by $15 \%$, by the year 2020 and further by $30 \%$ by 2025 (MOHFW, 2014).

The high prevalence of tobacco use (smoking and smokeless tobacco) and diverse ways in which the tobacco is consumed and marketed in India adds complexity to the tobacco control landscape and poses a significant challenge for effective implementation of WHO FCTC in India (WHO India, 2013). At an individual level, tobacco use tends to have a very high opportunity cost due to absence of adequate health provision, leading to high-out-of pocket expenses in India, thus, resulting in reduced capacity to seek better education, health and nutrition (Panda et al., 2012). At the population level, it is estimated that an increase in tobacco users (due to population growth), with limited health care provision, will lead to unprecedented diseases and deaths (WHO, 2008 (a)). The estimated economic cost of tobacco in 2011, US\$22.4 billion, was $12 \%$ more than the combined expenditure of national and 
state governments on health in the period 2010-11, and calls for complete implementation of WHO FCTC and tobacco control legislation in India (MOHFW, 2014). Thus, there is need to examine the challenges faced by tobacco control in India vis-à-vis WHO FCTC, because its effective implementation will be pertinent to control the tobacco epidemic in the country while reducing the health (cardiovascular, tuberculosis, cancers and respiratory diseases) and financial consequences (owing to the treatment) of tobacco attributable diseases in future (John, 2005; WHO, 2012 (a); MOHFW, 2014).

\section{Methodology:-}

For accomplishing literature review on critically analyzing the challenges in implementing WHO FCTC in India, the literature search was performed using four bibliographic databases (Medline, IBSS, ASSIA and web of science) during $15 / 5 / 2014$ to $15 / 6 / 2014$. The time frame used for searching the literature was 2004-2014, as it was only in February 2004, that India ratified the WHO FCTC. Further, studies published in english language were included for the search. The following search terms were used for conducting the literate review: String I: Tobacco control AND India, String II: WHO FCTC AND India and String III: Tobacco AND policy AND implementation AND India

The initial search in four databases using the search strings I, II, and III, amounted to a total 516,13 and 23 hits respectively. In order to reach to the final list of reviewed literature, filtering was conducted in two phases, firstly, initial scoping of literature was conducted by reading the abstract and title of the academic literature to narrow it down to 68, and secondly, relevant literatures identified in the first phase (excluding duplicates) were thoroughly read and only those studies whose primary research was directly related to the research objective, including tobacco control policy, WHO FCTC, tobacco legislation and its implementation or challenges in India were selected. This provided a final list of 15 articles. Also, an attempt was made to identify further articles which were cited as references to the final articles (snowballing). This method could further identify 5 relevant articles, affirming that most of the relevant literature was identified in the literature search. Out of these five, three articles identified were peer review articles and two were policy documents.

The extensive policy documents and reports have been added to the peer-reviewed literature for addressing the research objective. These policy documents were sourced through a wide ranging and extensive databases and were grouped for the purpose of ease into three major sub-groups. The first part belonged to the documents and reports sourced from WHO/ other UN, and national organizations. The second sub-group comprised of Government reports/notifications/publications ministries. The third part of the literature consists of reports and publications of NGOs part of the Framework convention alliance, membership of influential NGOs worldwide having voice over tobacco control globally (Fctc.org, 2014).

\footnotetext{
Results:-

Ineffective tobacco control enforcement, weak capacity and limited resources for implementation of the provisions of WHO FCTC \& COTPA in the States:-

An effective tobacco control legislation and enforcement requires coordination and collaboration between the central and state governments (Mehrotra et al., 2010). Many states in India are grappling with public health priorities of reducing high maternal and child mortality, therefore, priority of tobacco control varies across the states (Jagdish and Mohan, 2012). Moreover, the role of central government is limited to building capacity and providing technical and financial resources to states, however, the responsibility of enforcement of legislation lies with the state governments and level of implementation varies from one state to the other (Jagdish and Mohan, 2012). There is lack of commitment and willingness at the level of senior bureaucratic administration in states to implement and coordinate activities of WHO FCTC (WHO India, 2013). It is compounded by lack of coordination between enforcement agencies within the State and low awareness among policy makers and other key stakeholders in the states for provisions under COTPA and WHO FCTC (Jagdish and Mohan, 2012; Kaur and Jain, 2011).
}

There has been absence or lack of training among the enforcement officials of various departments such as food, health, police, transport etc. who are entrusted the responsibility of enforcing the provisions of COTPA (including WHO FCTC) (Kaur and Jain, 2011). This leads to poor enforcement of the provision of COTPA, due to failure to initiate action in case of violations and thus, resulting in its ineffective implementation (Jagdish and Mohan, 2012). To counter this issue, the Government of India organized 5 regional level advocacy workshops followed by 11 state level workshops in the year 2009 with various stakeholders on tobacco control efforts and initiated the development of training modules and advocacy materials on provisions of COTPA, WHO FCTC and NTCP in the year 2008-09 
(Jagdish and Mohan, 2012; Kaur and Jain, 2011). As a result of these workshops, around 2000 stakeholders were sensitized about the various provisions/articles under COTPA and WHO FCTC (Jagdish and Mohan, 2012; Kaur and Jain, 2011). However, as pointed out as a major constraint to implementation of WHO FCTC in implementation reports over the years is "Lack of adequate resources for capacity building at state level for implementation of the provisions of the tobacco control laws" (MOHFW, 2007:16; 2010: 60).

A cross sectional study was conducted in Odisha, eastern state of India to assess the level of enforcement of COTPA in the state, which included respondents from varied socio-economic backgrounds across 8 districts (Panda et al., 2012). The findings revealed that only $52 \%$ of the respondents were aware of tobacco control laws, $66.6 \%$ of people reported to have not seen any mandatory signboards at the point of sale (FCTC Article -13) and 36.2\% of respondents had never seen tobacco products sold with pictorial warnings (FCTC Article -11) (Panda et al., 2012). A study conducted among local government representatives in two districts of Kerala regarding their knowledge of framework convention and implementation of provisions under WHO FCTC, points out that first, a high knowledge about the provisions of WHO FCTC, does not translate into its effective implementation at the ground level (Mohan et al., 2013). This is because there are several other challenges at the local level which impact implementation of FCTC such as lack of administrative support, public opposition and lack of financial and human resources (Mohan et al., 2013). Secondly, the findings from the study show that awareness about the provisions of WHO FCTC, is offset by inadequate knowledge about the ill-effects of tobacco use, as one-third of representatives think that smoking upto 3 cigarettes a day will not generate any negative health impact (Mohan et al., 2013). Thus, this calls for comprehensive training of the representatives at the local and district level, and increased awareness about tobacco control for influencing public opposition of the provisions (Mohan et al., 2013).

Further, as per the evaluation of implementation of COTPA under the National Tobacco Control Programme in 21 states, only $52 \%$ of states have ensured monitoring mechanisms as per law (Kaur and Jain, 2011). Only 11 out of 15 states have established systems of collection of fines in order to enforce smoke free laws (FCTC Article -8) and only 3 out of 21 states have initiated the systems of enforcing fines under the (FCTC Article 13) / Section -5 of COTPA on ban on advertising, promotion and sponsorship (Kaur and Jain, 2011). This shows that there is an urgent need for establishing the systems for enforcement, and ensuring its implementation for greater compliance of the provisions of FCTC.

The analyses of implementation reports submitted by the ministry of health and family welfare to the WHO FCTC suggests that there have been various attempts by the government to train and educate the law enforcers, civil society organizations and health workers about the provisions of WHO FCTC in the States (MOHFW, 2007; 2010). However, these initiatives, including the capacity building of state level officers have been hindered due to inadequate financial resources under the national programme (MOHFW, 2010).

\section{Pattern of tobacco consumption with high prevalence and easy availability of smokeless forms of tobacco in India:-}

As per the Global adult tobacco survey (GATS) 2009-10, standardized survey (international) to track tobacco use and consumption, around 35\% (274.9 million) of adults use any form of tobacco in India with $21 \%$ (163.7 million) using only smokeless tobacco, 9\% (68.9 million) using only smoke and 5.3\% (42.3 million) using smoke and smokeless form of tobacco (IIPS, and MOHFW, 2010). Further, 5.3\% tobacco users $(9.3 \%$ of males and $1.3 \%$ of females) which use both smoking and smokeless tobacco products pose a significant challenge in terms of higher duration and doses of tobacco use, resulting in both difficulties in quitting and greater likelihood of suffering from tobacco related diseases (Bhawna, 2013). As indicated by WHO India, 2013: Factors contributing to the complexity of tobacco control in India: are the availability, affordability and easy access to plethora of low-cost and locally produced tobacco products, and the many ways in which the tobacco is produced, marketed and consumed in India (WHO India, 2013: 9)

A cross-sectional survey was conducted in 24 States and UTs of India based on the data from the Consumer Expenditure Survey (CES) of the 66th round of the National Sample Survey (Agarwal et al., 2013). As per the study, around $52 \%$ of households reported using some form of tobacco with dominance of smokeless tobacco (22\%), followed by bidi (17\%) and cigarettes (4\%) (Agarwal et al., 2013). Further, the study found huge interstate variation in pattern of smoking and smokeless form of tobacco and concluded that an increase in household income was associated with usage of cigarettes and bidi but not of smokeless tobacco. Also an increase in the education levels was associated with lower consumption of bidi and smokeless tobacco, but not of cigarettes (Agarwal et al., 2013). 
However, the study fails to provide information at the individual level, depict the relationship between socioeconomic status and tobacco use in the states over time, and how this relationship is impacted by the tobacco control policies at the national and state levels (Agarwal et al., 2013).

Further, the tobacco control efforts in India have to focus on reducing not just smoking, but also diverse forms of smokeless tobacco which are equally harmful, highly prevalent, and users of which are more likely to be less aware and poor (Bhawna, 2013; Agarwal et al., 2013). It is compounded by regional, socio-economic, cultural and religious variations in the consumption which further complicates tobacco control landscape in the country and poses challenges for implementing various provisions under WHO FCTC in India (Bhawana, 2013; IIPS and MOHFW, 2010). For this reason, the unique pattern of tobacco consumption in India along with high prevalence of a variety of smokeless forms of tobacco has been consistently reported as a major barrier for effective implementation of WHO FCTC in India for the past seven years (MOHFW, 2007; 2010; 2012 (a)). As per the FCTC implementation report 2012, "India is the second largest producer and consumer of tobacco products in the world and a plethora of tobacco products (both smoking and smokeless) are used in India” (MOHFW, 2012 (a)): 61), has been reported as a major constrain to the implementation of WHO FCTC in the country.

Under the context of India's diverse taxation approaches, the pattern of tobacco consumption complicates assessment of appropriate taxation (FCTC article -6) on tobacco products (John et al., 2010) and makes it difficult to suitably tax all types of tobacco products (especially bidis and smokeless form of tobacco), with periodic revision in the same, considering the inflation and consumers purchasing power (MOHFW, 2012 (b)).

Also, due to the pattern of tobacco use, the national and state level policies have to specifically target consumption of bidis and smokeless forms especially among poor (Bhawana, 2013). Hence, this means that the tobacco control strategies should be culturally acceptable and tailored to the local context (based on locally generated evidence) to be effective. This task is particularly challenging due to inadequate tobacco control research in the country especially on social determinants of tobacco use and effectiveness of tobacco control strategies among various socio-economic and cultural groups, resulting in gaps between generation of knowledge and its use in decision making (Panda et al., 2013, WHO, 2010; Bhawana, 2013).

There are a variety of smokeless forms of tobacco products consumed in India and the most popular forms are khaini (18\%), followed by gutka (13\%) and betel-quid (8\%) (IIPS and MOHFW, 2010). This high prevalence of smokeless forms of tobacco is attributable to the cultural and social acceptance of smokeless tobacco products in India vis-à-vis tobacco smoking (Bhawna, 2013). In the absence of strict ban on indirect advertising in the country, the marketing strategies of the manufacturers of smokeless products vary by type of product with rampant indirect advertising in the form of sponsorship of events and religious festivals (WHO, n.d (a)).

Tobacco industry's opposition to tobacco legislation resulting in delay and dilution of the provisions under WHO FCTC:-

Globally, the influence of tobacco industry has impede multi-sectoral coordination necessary for effectively implementation of WHO FCTC and influence policy making and legislation either through the ministry of health or other government ministries (UNDP, 2014). In India, the tobacco industry's interference through litigation has been one of the biggest threats to effective implementation of the framework convention, resulting in delay and dilution of the tobacco control legislation in the country (WHO, n.d (a); MOHFW, 2004; Arora et al., 2012 (a); Reddy et al., 2008; Oswal et al., 2010).

Also pointed out as a major constrain to effective implementation of WHO FCTC is "Number of court cases challenging the provisions of the Tobacco Control Act/Rules which is hindering its effective implementation" (MOHFW, 2010: 60). Further it is mentioned that "No action is initiated against the tobacco industry e.g. filing legal suits for compensation etc. at personal level or by the civil society" (MOHFW, 2010: 61). Oswal and others have also pointed out that "Unfortunately, the interference by the tobacco industry in health policy continues to be one of the greatest threats to the global tobacco treaty's implementation and enforcement" (Oswal et al., 2010: 3).

From time to time, the tobacco industry in India has contested for tobacco control legislation in the courts and slowed and weakened enforcement of smoke-free policies, pictorial warnings on tobacco products, tobacco advertising, promotion and sponsorship bans (Kaur and Jain, 2011). For example, the rules under COTPA, were 
notified in the year 2004-06, but the government of India had to face a series of backlash by the tobacco industry which opposed most of these rules and ultimately it was only in 2008-09 that the smoke free laws (FCTC Article -8) and laws on pictorial warning (FCTC Article -11) came into effect (Kaur and Jain, 2011). The industry had also opposed against the government's decision which prohibited the use of tobacco in toothpastes and toothpowders because it infringes upon the fundamental right to conduct trade or business (MOHFW, 2004). However, after the legal battle, the Supreme Court of India gave its verdict in favour of the Government because the ban was justified in public interest (MOHFW, 2004).

The tobacco industry's opposition to delay pictorial warning on tobacco products is particularly noteworthy. As a multilingual country (22 different official languages in India), with high rate of illiteracy, it is very important that effective pictorial warnings are enforced depicting negative health impact of tobacco use universally to tobacco users as well as non-users (Arora et al., 2012 (a); Reddy et al., 2010). As per COTPA's section 7 and WHO FCTC's article 11, effective pictorial warnings are mandatory on tobacco products and are meant to be a deterrent to tobacco use (Arora et al., 2012 (a)). On the recommendations of the Ministry of health and family welfare, the Government of India in the year 2006, field tested and notified effective pictorial warnings (50\% display area on both sides) for smoking and smokeless tobacco products, and the same was implemented in the year 2007 (Arora et al., 2012 (a); Reddy et al., 2010). However, due to immense pressure from the tobacco lobby in the country, these pictorial warnings were replaced with ineffective, smaller and non-field tested tobacco warnings in 2009 covering only $40 \%$ of display area in front (Arora et al., 2012 (a); Reddy et al., 2010). This was made possible due to opposition of the tobacco industry on pictorial warnings through lobbying, fabricated media reports and litigations (Reddy et al., 2010). Also, the immense pressure and influence of the Bidi industry, led the Group of Ministers to oppose the recommendations of the Ministry of health and family welfare, and finally display of skull and cross bones were removed by amendment in COTPA (on the pretext that these hurt religious sentiments of certain groups), resulting in dilution of pictorial warnings of tobacco products (Reddy et al., 2010; Arora and Yadav, 2010). Furthermore, the wholesale packs of Bidis were completely exempted from depicting pictorial warnings (Arora and Yadav, 2010). However, the Government of India finally notified new, improved and stringent pictorial warnings in the year 2011 (Arora et al., 2012 (a); WHO, n,d (a)).

It is also crucial to note the way in which the tobacco control efforts are stalled and delayed by highly fragmented smokeless tobacco industry consisting of khaini, gutka, mawa, gudhaku, and zarda (WHO, n,d (a); Arora and Yadav, 2010). For instance, field tested and effective pictorial warning of $40 \%$ on the smokeless tobacco products were first notified in 2006, but due to immense pressure from the smokeless tobacco lobby, these were replaced with non-field tested and less effective pictorial warnings in 2009 (WHO, n,d (a))

\section{Discussion:-}

The effective implementation of provisions under WHO FCTC is largely contingent upon the effective coordination between centre and state governments, coordination among various enforcement agencies in the states and the capacity of the concerned state governments (Mehrotra et al., 2010; Jagdish and Mohan, 2012; Reddy et al., 2010). Due to lack of capacity and limited priority to tobacco control in states, effective coordination among different enforcement agencies suffers coupled with weak monitoring and reporting on violations of COTPA and WHO FCTC (Jagdish and Mohan, 2012; Kaur and Jain, 2011). Thus, this impacts effective implementation and inadequate reporting further limits the scope of data to address implementation gaps (Panda et al., 2012; Kaur and Jain, 2011).

The evaluation of implementation of COTPA in states, clearly suggest that there is weak implementation, inadequate systems and poor reporting in 21 states under the National Tobacco Control Programme (Kaur and Jain, 2011). Also, given the capacity and financial constraints in various states, as a short term strategy, it is important to focus on implementing certain provisions under FCTC which are easier to enforce such as smoking and advertising bans and to ensure its full compliance by the states (Mohan et al., 2013). As a long term strategy, there is a need for establishing a comprehensive mechanism for monitoring, enforcement and coordination of WHO FCTC in the states along with increased allocation of dedicated human and financial resources for tobacco control and intensifying advocacy and training among all stakeholders (Panda et al., 2012; Mohan et al., 2013).

The pattern of tobacco consumption in India with very high prevalence and availability of smokeless forms of tobacco, poses a significant and unique challenge to tobacco control implementation in India. This creates challenges for the national programme especially in awareness generation (FCTC article -12), as different types of users of tobacco products such as Bidis, cigarettes and smokeless forms spread in urban/rural areas and belonging to different socio-economic and educational backgrounds needs to be reached out through different mediums 
(television, radio, print and movies) and messages (which can influence their respective social attitudes towards tobacco use). Thus, firstly, the government has to focus its limited resources under tobacco control on awareness generation through various mediums and secondly, to get the desired behavior change especially among the semiliterate and illiterate tobacco users in rural areas is challenging.

The tobacco consumption pattern with a very high percentage of people consuming both smoking and smokeless forms of tobacco, makes implementation of FCTC article -6 on adequate taxation of tobacco products challenging, since as a result of increase in taxation, the users of tobacco products simply switch their preference to less taxed tobacco products such as Bidis and smokeless forms tobacco or vice-versa (Agarwal et al., 2013) and thus, taxation, which is the strongest demand reduction measure globally, may or may not result in the desired reduction in tobacco consumption in the India unless all forms of the tobacco products are taxed simultaneously. The dynamic pattern of consumption also limits the scope of one size fits all (standardized) approach to tobacco prevention in the states and needs that the prevention efforts are suitable and relevant to local context. This calls for effective translation of international best practices of WHO FCTC into (context specific) policy and generation of new knowledge within the country to tackle the unique tobacco consumption pattern in India (WHO, 2010; Panda et al., 2013). However, India lacks resources and capacity for both of the above mentioned types of research and this severely limits evidence informed and context specific solutions for effective implementation of tobacco control locally and regionally within the country (Panda et al., 2013).

The opposition from a diverse and powerful industry (cigarettes, Bidis and smokeless tobacco) in the form of litigations against the government makes tobacco control landscape fairly complex and results in delay and dilution of legislation in India (WHO, n.d (a); Reddy et al., 2010). The case of delay in enforcement of pictorial warnings suggests that India's tobacco control efforts have to withstand not just a strong and organized cigarettes lobby, but an equally powerful Bidi and unorganized smokeless tobacco industry which engages and influences the government to dilute and delay implementation of crucial provisions (Arora et al., 2012 (a); Arora and Yadav, 2010). Such systematic opposition to crucial provisions under WHO FCTC (pictorial warnings and smoke free laws) by the diverse players of tobacco industry damages tobacco control efforts in the country. It is also important to note that the three major challenges identified often operate in tandem to impact effective implementation of WHO FCTC in India. While, the opposition from tobacco industry leads to delay and dilution in the enforcement of various provisions within the WHO FCTC, once they are enforced, the weak capacity and limited resources in the states directly impacts its effective implementation and finally, the pattern and variation of tobacco consumption (smoking and smokeless) in India, further makes the implementation and execution of the national programme and WHO FCTC complex and difficult.

\section{Conclusion:-}

The effective implementation of WHO FCTC in India is very crucial to address the tobacco epidemic in the country and to reduce the economic and health costs of tobacco attributable diseases in the future (John, 2005; WHO, 2012 (a); MOHFW, 2014). India has come a long way since 2004, when it first ratified the treaty, in implementing various provisions under the WHO FCTC (MOHFW, 2007; 2010; 2012 (a)). However, almost after ten years, there are many challenges to its effective implementation such as ineffective tobacco control enforcement with limited resources and weak capacity for implementation of the provisions of WHO FCTC in States. This is compounded due to weak coordination between Centre and State governments and among various enforcement agencies within the States, inadequate training of the enforcement officials, limited human and financial resources and weak reporting and monitoring of non-compliance of the provisions of WHO FCTC (Jagdish and Mohan, 2012; Kaur and Jain, 2011; MOHFW, 2010). The pattern of tobacco consumption with high prevalence and availability of smokeless forms of tobacco makes the implementation of various provisions under WHO FCTC complex and challenging (WHO India, 2013; Bhawana, 2013). This is further magnified due to inadequate local and country level tobacco control research, resulting in policy level knowledge gap in the country (Panda et al., 2013). The systematic opposition by multiple players of tobacco industry to tobacco control policies and legislation in the country, results in delay and dilution of the provisions under WHO FCTC in India (Arora et al., 2012 (a); Reddy et al., 2010; Oswal et al., 2010).

To meet the challenges in effective implementation of WHO FCTC in India, there is a need for increased allocation of financial resources in all 21 States where the national tobacco control programme is currently being implemented along with periodic training and capacity building of enforcement officials in the states. Greater coordination both between the centre and state governments as well as within the state between various enforcement agencies is 
required, with sustained advocacy with the local and state government representatives, policy makers, civil society and other key stakeholders. There is also a need to strengthen the systems of monitoring, evaluation and reporting of the national programme on provisions of WHO FCTC in the states. The role of civil society, consumer organizations and judicial activism must be encouraged to deal with the influence of the tobacco industry on tobacco control policy and legislation (MOHFW, 2004).

\section{References:-}

1. Agrawal, S., Karan, A., Selvaraj, S., Bhan, N., Subramanian, S. and Millett, C (2013) 'Socio-economic patterning of tobacco use in Indian states'. The International Journal of Tuberculosis and Lung Disease, 17(8),pp.1110-1117

2. Arora, M. and Yadav, A.(2010). 'Pictorial health warnings on tobacco products in India: sociopolitical and legal developments'. National Medical Journal of India, 23(6), p.357.

3. Arora, M, Tewari, A, Nazar, G, Gupta, V, \&amp; Shrivastav, R. (2012 (a)), \&\#39;Ineffective pictorial health warnings on tobacco products: lessons learnt from India\&\#39; Indian Journal Of Public Health, 56, 1, pp. 6164, viewed 25 July 2014.

4. Bhawna, G. (2013), \&\#39;Burden of Smoked and Smokeless Tobacco Consumption in India - Results from the Global adult Tobacco Survey India (GATS-India)- 2009-2010\&\#39; Asian Pacific Journal Of Cancer Prevention, 14,5, pp. 3323-3329, viewed 12 June 2014.

5. Fctc.org, (2014). FCA\&\#39; s Work. [online] Available at: http://www.fctc.org/about-fca/work- of-the- fca [Accessed 14 Jul. 2014].

6. International Institute for Population Sciences (IIPS), Mumbai and Ministry of Health and Family Welfare, Government of India (2010). Global adult tobacco survey India (GATS India), 2009-2010. New Delhi: Ministry of Health and Family Welfare. Available at: mohfw.nic.in/WriteReadData/1892s/1455618937GATS\%20India.pdf [Accessed: 21 July 2014].

7. Jagdish, K, \&amp; Mohan, P (2012), \&\#39;Advocacy for tobacco control in India - A step forward\&\#39;, Public Health (Elsevier), 126, 8, pp. 675-677, viewed 6 June 2014.

8. John, R (2005), \&\#39; Tobacco consumption patterns and its health implications in India\&\#39; Health Policy, 71, 2, pp.213-222, viewed 11 June 2014.

9. Kaur, J, \&amp; Jain, D (2011), \&\#39;Tobacco control policies in India: implementation \&amp; challenges\&\#39; Indian Journal of Public Health, 55, 3, pp. 220-227, viewed 10 June 2014.

10. Mehrotra, R, Mehrotra, V, \&amp; Jandoo, T (2010), \&\#39;Tobacco control legislation in India: past and present\&\#39;, Indian Journal of Cancer, 47 Suppl 1, pp. 75-80, viewed 9 June 2014.

11. Mohan, S., Mini, G. and Thankappan, K (2013). 'High knowledge of Framework Convention on Tobacco Control provisions among local government representatives does not translate into effective implementation: Findings from Kerala, India'. Public health, 127(2), pp.178-- 181.ISSN: 2320-5407 Int. J. Adv. Res. 5(7)

12. Ministry of Health and Family Welfare (2004). The Report on Tobacco Control in India. New Delhi: Ministry of Health and family welfare. Available at: http://www.who.int/fctc/reporting/Annexs6_Report_on_Tobacco_Control_in_India_2004.pdf [Accessed: 9 June 2014].

13. Ministry of Health and Family Welfare, (2007). The reporting instrument under the WHO framework convention on tobacco control 2005-07. New Delhi: Ministry of health and family welfare. Available at: http://www.who.int/tobacco/framework/cop/party_reports/india_report.pdf?ua=1 [Accessed: 21 June 2014].

14. Ministry of Health and Family Welfare, (2010). The reporting instrument under the WHO framework convention on tobacco control 2007-10. New Delhi: Ministry of health and family welfare. Available at: http://www.who.int/fctc/reporting/India_5y_report_final.pdf?ua=1 [Accessed: 21 June 2014].

15. Ministry of Health and Family Welfare, (2012 (a)). The reporting instrument under the WHO framework convention on tobacco control 2010-2012. New Delhi: Ministry of health and family welfare. Available at: http://www.who.int/fctc/reporting/party_reports/india_2012_report.pdf?ua=1 [Accessed: 21 June 2014].

16. Ministry of Health and Family Welfare, $(2012$ (b)). Operational guidelines- National Tobacco Control Programme. New Delhi: Ministry of Health and family welfare. Available at: http://mohfw.nic.in/WriteReadData/1892s/2945310979Operational\%20Guidelines.pdf [Accessed: 21 June 2014].

17. Oswal, K, Pednekar, M, \&amp; Gupta, P (2010), \&\#39;Tobacco industry interference for pictorial warnings\&\#39;, Indian Journal Of Cancer, 47, pp. S101-S104, viewed 7 August 2014. 
18. Panda, B, Rout, A, Pati, S, Chauhan, A, Tripathy, A, Shrivastava, R, \&amp; Bassi, A (2012), \&\#39;Tobacco Control Law Enforcement and Compliance in Odisha, India - Implications for Tobacco Control Policy and Practice\&\#39; Asian Pacific Journal Of Cancer Prevention, 13, 9, pp. 4631-4637, viewed 25 July 2014

19. Reddy, K, Arora M, Yadav A, (2008). A comparative analysis of WHO Framework Convention on Tobacco Control (FCTC) and the Indian laws regulating Tobacco. New Delhi: The Public health Foundation of India and Ministry of health and family welfare. Available at: http://rajswasthya.nic.in/Tobacco\%20Control\%20Resource\%20\&amp;\%20IEC\%20Materials\%20new/A\%20co $\underline{\text { mpar }}$

ative $\% 20$ analysis $\% 20$ of $\% 20$ WHO $\% 20$ FCTC $\% 20$ and $\% 20$ the $\% 20$ Indian $\% 201$ laws $\% 20$ regulating $\% 20$ tobacco.pd f [Accessed: 21 June 2014].

20. Reddy, K, Arora, M, Shrivastav, R, Yadav, A, Singh, D, Bassi, A (2010). Implementation of the Framework Convention on Tobacco Control (FCTC) in India- A Shadow Report-2010. New Delhi: Health Related Information Dissemination among Aouth. Available http://www.phfirc.org/ctchp.org/images/pdf5/updates/Reports/REPORT-

Implementation\%20of\%20FCTC\%20in\%20India\%20-\%20A\%20Shadow\%20Report_2010.pdf [Accessed: 21 June 2014].

21. United Nations Development Programme, (2014). Development Planning and Tobacco Control: Integrating the WHO Framework Convention on Tobacco Control into UN and National Development Planning Instruments. New York: United Nations Development Programme. Available at: http://www.undp.org/content/dam/undp/library/HIVAIDS/HIV\%20MDGs\%20and\%20Development\%20Planning/Development\%20Planning\%20and\%20Tobacco \%20 Control\%202014\%2002\%2028\%20PDF\%20FINAL.pdf [Accessed: 20 July 2014].

22. World Health Organization, (2003 (a)). WHO Framework Convention on Tobacco Control: Geneva: World Health Organization Available at: http://whqlibdoc.who.int/publications/2003/9241591013.pdf?ua=1 [Accessed: 25 June 2014]

23. World Health Organization (2008 (a)). WHO Report on the Global Tobacco Epidemic, 2008: The MPOWER package. Brazil: Horld Health Organization. Available http://www.who.int/tobacco/mpower/mpower_report_full_2008.pdf [Accessed: 25 June 2014].

24. World Health Organization (2012 (a)). WHO Global report on Tobacco attributable mortality. Geneva: World health organization. Available at: http://whqlibdoc.who.int/publications/2012/9789241564434_eng.pdf?ua=1 [Accessed: 26 June 2014]. ISSN: 2320-5407 Int. J. Adv. Res. 5(7)

25. World Health Organisation India, (2013). The role of intersectoral action in implementing framework convention on tobacco control in India. New Delhi: World Health Organisation India Country Office. Available at: http://www.searo.who.int/india/tobacco/intersectoral_action_for_who_fctc.pdf?ua=1) [Accessed: 28 July 2014].

26. World Health Organization [n.d (a)]. Smokeless tobacco in South-East Asia in relation to the WHO FCTC, Regional study series Paper R/2 .[n.p]: World Health Organization Available at: http://apps.who.int/fctc/publications/Smokeless_tobacco_paper_2_22052014.pdf [Accessed: 28 July 2014]. 